\title{
CAPÍTULO 21: INFLUÊNCIA DO SECAMENTO PARCIAL DO SISTEMA RADICULAR NA QUALIDADE DE FRUTOS DO MARACUJÁ
}

\section{CHAPTER 21: INFLUENCE OF PARTIAL ROOTZONE DRYING ON FRUIT QUALITY OF PASSION FRUIT}

\author{
Gyovanni Keidy Zan Minakawa ${ }^{1}$; Nicolas Souza Soares ${ }^{2}$; Eduarda Alves Brexó ${ }^{3}$ Adriana Smanhotto \\ Soncela ${ }^{4}$; Rosimaldo Soncela ${ }^{5}$
}

\begin{abstract}
Resumo
A agricultura irrigada consome uma elevada quantidade de água no mundo, a técnica de secamento parcial da zona radicular pode ser uma alternativa para garantir a produtividade e reduzir a água aplicada. O objetivo deste trabalho foi avaliar o efeito da técnica do secamento parcial da zona radicular na produção e qualidade de frutos do maracujazeiro cultivar BRS Rubi do Cerrado, na Região do Vale do Ivinhema. O experimento foi instalado no campo experimental do Instituto Federal de Mato Grosso do Sul, campus Nova Andradina. O delineamento foi em blocos casualizados, com quatro tratamentos e três repetições. Os tratamentos consistiram em redução de $25 \%$ e $50 \%$ da ETc, alternando a cada 07 dias; irrigação plena, ou seja, $100 \%$ da ETc, alternando a cada 07 dias; irrigação plena, $100 \%$ da ETc - com irrigação dos dois lados da planta. Foram realizadas avaliações de comprimento do fruto, diâmetro médio do fruto, peso médio do fruto, casca e polpa. Não foram observadas diferenças na qualidade física dos frutos entre os tratamentos aplicados, indicando uma possibilidade na redução da lâmina de irrigação através da técnica do secamento parcial da zona radicular sem impacto negativo sobre os frutos.
\end{abstract}

Palavras-Chave: Manejo de irrigação, Irrigação Localizada, Maracujazeiro.

\begin{abstract}
Irrigated agriculture consumes a high amount of water in the world, the partial root zone drying technique can be an alternative to ensure productivity and reduce applied water. This paper aimed to evaluate the effect of the partial rootzone drying technique on production and quality of passion fruit from Cultivar BRS Rubi do Cerrado at Vale do Ivinhema region. The experiment was installed in the experimental field of Federal Institute of Education, Science and Technology of Mato Grosso do Sul, Nova Andradina campus. The design was in randomized blocks, with four treatments and three replications. The treatments consisted in $25 \%$ and $50 \%$ ETc reduction alternating every 7 days; full irrigation, that is, $100 \%$ of ETc, alternating every 07 days; full irrigation, $100 \%$ of ETc - irrigating both sides of the plant. Evaluations of fruit length, average fruit diameter, average fruit weight, peel and pulp were performed. No differences were observed in the physical quality of the fruits between the treatments applied, indicating a possibility in reducing the irrigation depth through the technique of partial drying of the root zone without negative impact on the fruits.
\end{abstract}

\footnotetext{
${ }^{1}$ Curso Bacharelado em Agronomia, Instituto Federal de Mato Grosso do Sul, gyovanni.minakawa@estudante.ifms.edu.br

${ }^{2}$ Curso Bacharelado em Agronomia, Instituto Federal de Mato Grosso do Sul, nicolas.soaresdiy@gmail.com

${ }^{3}$ Curso Bacharelado em Agronomia, Instituto Federal de Mato Grosso do Sul, dubrexo@gmail.com

${ }^{4}$ Doutora em Agronomia - Irrigação e Drenagem, Instituto Federal de Mato Grosso do Sul, adriana.smanhotto@ifms.edu.br

${ }^{5}$ Doutor em Engenharia Agrícola, Instituto Federal de Mato Grosso do Sul, rosimaldo.soncela@ifms.edu.br
} 
MINAKAWA, et al.

Keywords: Irrigation management, Localized irrigation, Passion fruit tree.

\section{Introdução}

O maracujazeiro-amarelo (Passiflora edulis f. flavicarpa) pertencente à família Passifloraceae, é uma frutífera nativa da região tropical da América do Sul, apresenta um ciclo semi-perene. Seu desenvolvimento é favorecido em regiões com temperaturas médias mensais entre $21^{\circ} \mathrm{C}$ a $32{ }^{\circ} \mathrm{C}$, e com precipitação pluviométrica anual entre $800 \mathrm{~mm}$ a $1750 \mathrm{~mm}$ (SOUSA; BORGES, 2011).

O Brasil é o maior produtor mundial de maracujá, no ano de 2015-2017 a produção mundial atingiu 1,4 milhões de toneladas, onde o Brasil contribui com cerca de 0,9 milhões de toneladas, a cultura é disseminada em todo o país, sendo que, no ano de 2018, a produção brasileira foi de 602.651 t (SATO et al., 1992; SANTOS et al., 2009; IBGE, 2018; ALTENDORF, 2018). Apesar de ser o maior produtor, possui uma baixa produtividade, mas proporciona um ótimo retorno econômico (MELETTI et al., 2010).

Nos últimos 30 anos, o cultivo de maracujá teve uma crescente expansão, ocupando um lugar de destaque na fruticultura tropical. Além disso, é de grande importância social no oferecimento de empregos no campo, tanto para micros até grandes produtores.. A cultura é uma ótima opção para os produtores, pois entra em produção rapidamente, oferta diferentes linhas de mercados, além de agregação de valor ao produto e os fruticultores optam, pois geram renda semanalmente durante o período de colheita (MELETTI et al., 2010; FALEIRO; JUNQUEIRA, 2016).

A cultura do maracujazeiro apresenta uma elevada demanda hídrica. De acordo com Ruggiero et al. (1996) e Costa (2008), quando exposta a uma deficiência hídrica prolongada, ocasiona paralisação vegetativo, atraso no florescimento, queda de flores e frutos, afetando negativamente na produtividade e qualidade de frutos. Por outro lado, o excesso de umidade no solo possibilita o aparecimento de patogênicos, mas comumente o desenvolvimento de podridões radiculares, no qual é um dos fatores limitantes da cultura (CASTRO; KLUGE, 1998).

A irrigação proporciona aos produtores maior garantia de produção, melhora na utilização dos recursos naturais e aumenta a produtividade, logo permite melhor retorno financeiro (SOUSA et al., 2001; ARAÚJO et al., 2012). O sistema por gotejamento tem sido preferível pelos produtores, pois permite condições de umidade e aeração no solo, favorecendo o pleno desenvolvimento das plantas e a produção do maracujazeiro (LIMA et al., 2011). 
De acordo com Costa et al. (2000), o método de irrigação que destaca-se é de irrigação localizada tanto por gotejamento ou microaspersão, de forma a controlar a lâmina de água aplicada e a maior eficiência do uso d'água. Além disso, reduz a disseminação de patógenos e minimizar a perda por evaporação, percolação e escoamento superficial.

Para obter uma produção satisfatória e um bom retorno financeiro, deve-se optar por um manejo de irrigação racional, aplicando-se no período correto a quantidade adequada de água. Conforme Sampaio et al. (2010), a agricultura irrigada consome uma elevada quantidade de água no mundo, com uma tendência de escassez dos recursos hídricos, dessa forma é necessário empregar técnicas de irrigação que otimiza a eficiência do uso de água.

De acordo com FAO (2002), para aumento da eficiência do uso de água, a técnica de irrigação com déficit hídrico, é uma alternativa para agricultura irrigada, podendo levar maiores ganhos econômicos. Esse método entende-se em irrigar alternadamente lados diferentes de uma planta, em frequências que dependerão do sistema solo-planta-atmosfera.

O déficit hídrico controlado pela estratégia do secamento parcial do sistema radicular tem indicado que é possível aumentar a eficiência de uso da água pelas culturas, com redução do crescimento vegetativo, mantendo-se a produção em uma escala satisfatória (DRY; LOVEYS, 1998).

Considera-se que o sistema radicular passa a metabolizar uma maior quantidade de ácido abscísico (ABA), que se transloca pelo eixo vascular, concentrando-se na parte aérea e promovendo o fechamento parcial dos estômatos e, conseguinte, resulta em menor evaporação de água para a atmosfera (GOWING et al., 1990; DAVIES; ZHANG, 1991; DAVIES et al., 2002).

Normalmente as plantas abrem seus estômatos para captar $\mathrm{CO}_{2}$ e perdem água nas trocas gasosas. Contudo, as plantas devem ser capazes de detectar o déficit de umidade no solo e equilibrar seu consumo de água. Com isso, o mecanismo regulador estomático ativa-se antes da água disponível no solo seja escassa (FARQUHAR; SHARKEY, 1982; JONES, 2014; CARVALHO, 2015).

Para Davies; Zhang (1991) e Jones (2014), a técnica de secamento parcial da zona radicular, entende-se que as raízes no solo em processo de secagem, emite um sinal que alcança a parte aérea, comunicando o fechamento estomático e redução de perda de água pela transpiração, logo, esse fechamento estomático reduz a perda de água, não comprometendo drasticamente a fotossíntese.

No entanto, o método de secamento parcial do sistema radicular em frutíferas ainda são pouco pesquisado, não tendo resultados consolidados da técnica, em função da heterogeneidade 
dos solos cultivados, assim como, a resposta de crescimento da planta nas diferentes estações do ano. Dessa forma, há necessidade de conhecer com maior precisão a resposta das culturas ao déficit, uma vez que varia de espécie e estágio de crescimento (FAO, 2002).

O objetivo deste trabalho foi verificar os efeitos da técnica do secamento parcial da zona radicular sobre a produtividade do maracujazeiro, assim como, os índices de produção e qualidade dos frutos a fim de determinar a quantidade de água que pode reduzir sem interferência negativa na produção.

\section{Material e Métodos}

O experimento foi conduzido nas dependências do Instituto Federal de Educação, Ciência e Tecnologia de Mato Grosso do Sul - IFMS, localizado na Fazenda Santa Bárbara, s/n, situada a $20^{\circ} 04^{\prime} 47,98^{\prime \prime}$ e a $53^{\circ} 57^{\prime} 16,46^{\prime \prime}$ W com altitude de 357 metros, no município de Nova Andradina - MS. O solo é classificado como Latossolo Vermelho Distroférrico de textura arenosa (EMBRAPA, 2006).

O clima predominante na região é o tropical, quente e semiúmido, marcado por chuvas no verão e períodos secos durante o inverno. O índice pluviométrico anual é elevado com média variável de 1.400 a $1.700 \mathrm{~mm}$, apresentando déficit hídrico entre abril e dezembro (EMBRAPA, 2006).

O delineamento utilizado no experimento foi em blocos casualizados, com quatro manejos de irrigação e três repetições, totalizando 12 parcelas experimentais. Cada parcela foi composta por seis plantas, espaçadas de $5 \mathrm{~m}$ entre plantas e $3 \mathrm{~m}$ entre linhas de plantas, sendo que quatro plantas foram úteis e as demais serviram com bordadura. Os manejos da irrigação foram baseados na redução da lâmina bruta calculada, sendo: redução de $25 \%$ da ETc, alternando a cada 07 dias (T1); redução de 50\% da ETc, alternando a cada 07 dias (T2); irrigação plena, ou seja, 100\% da ETc, alternando a cada 07 dias (T3); irrigação plena, ou seja, $100 \%$ da ETc - testemunha - com irrigação dos dois lados da planta (T4).

O volume de água aplicado no tratamento testemunha foi estimado pela evapotranspiração da cultura (BERNARDO et al., 2006), calculado por meio das medidas de evapotranspiração de referência (ETo), utilizando uma média de ETo de 4,2 $\mathrm{mm} \mathrm{dia}^{-1}$, obtida através do trabalho realizado por Flumignan et al. (2016), através do banco de dados da Estação Agrometeorológica da Embrapa Agropecuária Oeste, localizada em Dourados, MS e pelo coeficiente da cultura (Kc) médio igual a 0,6 (CARVALHO et al., 2001), de acordo com a Equação 1. 
MINAKAWA, et al.

$$
\mathrm{ET}_{c}=E T_{0} * \mathrm{Kc}
$$

Sendo:

$\mathrm{Et}_{\mathrm{c}}=$ evapotranspiração da cultura, em $\mathrm{mm} \mathrm{dia}^{-1}$;

$\mathrm{ET}_{0}=$ evapotranspiração de referência, em $\mathrm{mm} \mathrm{dia}^{-1}$;

$\mathrm{Kc}=$ coeficiente da cultura do maracujá.

O tempo de irrigação (Equação 2) foi determinado para cada manejo, uma vez que em cada linha foi colocado dois emissores gotejadores autocompensantes de $4 \mathrm{~L} \mathrm{~h}^{-1}$ de acordo com o fabricante distantes $30 \mathrm{~cm}$ de cada planta. Também foi realizado o teste de vazão média dos gotejadores e ajustado para o tempo de irrigação.

$$
T i=\frac{I T N}{I a}
$$

Sendo:

$\mathrm{Ti}$ = tempo de irrigação, horas;

ITN = Lâmina Bruta de Irrigação $(\mathrm{mm})$, determinada pela evapotranspiração da cultura calculada na equação 1;

Ia = Intensidade de Aplicação, calculada em $\mathrm{mm} \mathrm{h}^{-1}$, conforme equação 3.

$$
I a=\frac{q * n}{E_{p} * E_{l p}}
$$

Sendo:

Ia = Intensidade de Aplicação, calculada em $\mathrm{mm} \mathrm{h}^{-1}$;

q= vazão dos gotejadores (média de $4,158 \mathrm{~L} \mathrm{~h}^{-1}$ );

$\mathrm{n}=$ número de gotejadores por planta (2 para os manejos alternados e 4 para os manejos de irrigação plena dos dois lados);

$\mathrm{E}_{\mathrm{p}}=$ espaçamento entre plantas, metros;

$\mathrm{E}_{\mathrm{lp}}=$ espaçamento entre linhas de plantas, metros.

A lâmina de irrigação calculada foi de $2,52 \mathrm{~mm} \mathrm{dia}^{-1}$, e os tempos de irrigação variaram de 4,54 horas (irrigação plena, 100\% da ETc, alternando a cada 07 dias e irrigação plena, 100\% da ETc - testemunha - com irrigação dos dois lados da planta), 3,40 horas (redução de 25\% da ETc, alternando a cada 07 dias) e 2,27 horas (redução de 50\% da ETc, alternando a cada 07 dias). 
O estudo foi conduzido no período de março de 2019 a julho de 2020. Foi realizada a coleta do solo para a caracterização da área experimental, nas profundidades de $0-20 \mathrm{~cm}, 20$ $-40 \mathrm{~cm}$ e $40-60 \mathrm{~cm}$ (Tabela 1).

Tabela 1. Caracterização química do solo antes da instalação do experimento nas diferentes profundidades.

\begin{tabular}{|c|c|c|c|c|c|c|c|c|c|c|c|c|c|}
\hline MO & $\mathrm{P}$ & B & $\mathrm{S}$ & $\mathrm{Ca}$ & $\mathrm{Mg}$ & $\mathrm{K}$ & $\mathrm{Al}$ & $\begin{array}{c}\mathrm{H}+\mathrm{A} \\
1\end{array}$ & $\begin{array}{c}\text { Som } \\
\text { a de } \\
\text { base } \\
s\end{array}$ & $\begin{array}{l}\text { CTC } \\
\text { pH } 7\end{array}$ & $\begin{array}{c}\text { CTC } \\
\text { efeti } \\
\text { va }\end{array}$ & $\begin{array}{c}\text { Sat. } \\
\text { Al }\end{array}$ & $\begin{array}{c}\text { Sat. } \\
\text { Bases }\end{array}$ \\
\hline $\mathrm{g} / \mathrm{dm}^{3}$ & -----. & $\mathrm{mg} /$ & ----- & ----- & ----- & $\ldots$ & molc & $m^{3}$ & 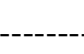 & & ------. & & $\%$ \\
\hline
\end{tabular}

$00-20$

\begin{tabular}{llllllllllllll}
10,54 & 4,73 & 0,15 & 4,29 & 0,62 & 0,2 & 0,04 & 0,52 & 4,99 & 0,86 & 5,85 & 1,38 & 37,68 & 14,7 \\
\hline
\end{tabular}

$20-40$

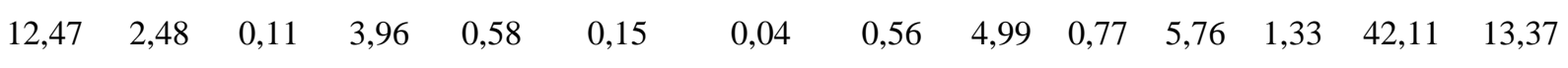

$40-60$

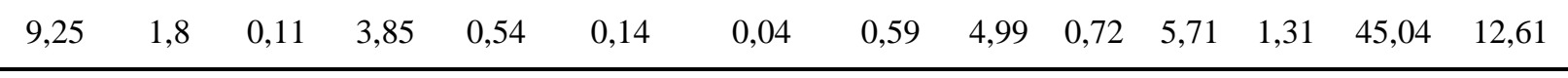

A área foi preparada utilizando arado de aiveca na profundidade de $40 \mathrm{~cm}$ e finalizado com duas gradagem aradora intermediaria. Após foram abertas covas de plantio com perfurador de solo acoplado ao trator, aplicando $200 \mathrm{~g}$ de calcário dolomítico, $50 \mathrm{~g}$ de $\mathrm{P}_{2} \mathrm{O}_{5}, 50 \mathrm{~g}$ de $\mathrm{K}_{2} \mathrm{O}$ e $8 \mathrm{~L}$ de esterco de curral em cada cova.

As mudas foram produzidas no mês março de 2019, utilizando a variedade Rubi do Cerrado e a semeadura das sementes foi feita em tubetes, utilizando um substrato com $50 \%$ solo e 50\% húmus de minhoca, ao surgir as primeiras folhas verdadeiras foi aplicado uma solução nitrogenada com 0,6 g de uréia diluída em 2 L de água, para o arranque inicial das plântulas, esse processo foi repetido por $3 \mathrm{vez}$ a cada sete dias. Quando as plantas atingiram 4 folhas expandidas, foram transplantadas para sacos plásticos de polietileno.

O sistema de irrigação localizada foi instalado, composto por um conjunto motobomba de $1 \mathrm{cv}$ e em cada parcela experimental foram instaladas duas linhas laterais de polietileno de $16 \mathrm{~mm}$, com 2 emissores gotejadores do lado direito e 2 do lado esquerdo, totalizando 4 
MINAKAWA, et al.

gotejadores por planta. No início de cada linha lateral foi instalado registro para abertura e fechamento, o que permitia a alternância dos manejos.

As plantas foram transplantadas na área experimental, após 120 dias da emergência, sendo estaqueadas, e amarradas com fitas plásticas (fitilhos) para auxiliar na condução até os arames e assim, evitar tombamentos e danificações. Após o plantio foi feito a adubação de acordo com Lima et al. (1994) e Andrade (2004). Aplicando-se 10 g de N e K por planta e após 30 dias do transplante realizando novamente.

A condução da cultura, foi do tipo espaldeira vertical, onde o tutoramento foi feito com auxílio de varões até as plantas alcançarem o arame da parreira, no qual foram implantadas numa altura de 2,20 m do solo. As brotações laterais foram sendo retiradas até alcançarem o arame e após a dominância apical foi cortada, estimulando as brotações laterais. As brotações, sempre eram conduzidas lateralmente pelo arame e realizada poda dos ramos laterais quando encontravam os ramos da outra planta.

No período de floração, observou um baixo número de insetos polinizadores, principalmente a mamangava (Xylocopa spp.), principal inseto polinizador. Dessa forma, realizou-se a polinização manual, com auxílio de hastes flexíveis de algodão, de forma alternada, transferindo os grãos de pólen de uma planta para outra, já que estas exigem polinização cruzada, sendo realizado nas horas mais quentes do dia das 11:00 AM às 15:00 PM, período em que grande parte das flores se mantém abertas e aptas a serem polinizadas.

A colheita dos frutos foi realizada de fevereiro a julho de 2020. A coleta dos frutos seguiu a metodologia de Hafle et al. (2009), conforme os frutos foram apresentando amadurecimento e caiam ao solo, eram realizadas as coletas e os frutos devidamente identificados, conforme a linha de irrigação e planta, diferindo-se dentre os tratamentos.

Foram realizadas as avaliações de peso médio dos frutos (g), peso médio de casca $(\mathrm{g})$ e peso médio de polpa (g), pesando-se em uma balança semi analítica, de acordo com a metodologia Instituto Adolfo Lutz (2008). Também foram feitas as análises do comprimento e diâmetro do fruto, utilizando-se paquímetro digital e os resultados expressos em milímetros $(\mathrm{mm})$.

Os dados foram submetidos à análise de variância pelo teste $\mathrm{F}$ e as médias dos tratamentos foram comparadas pelo teste Tukey ao nível de 5\% de probabilidade. Utilizandose o software SISVAR, versão 4.3 (FERREIRA, 2011), para realização dos cálculos estatísticos. 


\section{Resultados e Discussão}

Na Tabela 2 pode ser observado o resumo da análise de variância para os parâmetros avaliados. Verifica-se, que as variáveis analisadas para qualidade de frutos não apresentaram significância de acordo com os tratamentos aplicados. Tal fato, corrobora Crisóstomo; Naumov (2009) que relataram que o maracujazeiro apresenta uma moderada resistência ao estresse hídrico.

Tabela 2. Resumo da análise de variância para a obtenção dos valores de F, para o peso do fruto, peso da casca, peso da polpa, diâmetro e comprimento dos frutos de maracujá.

\begin{tabular}{|c|c|c|c|c|c|c|}
\hline \multirow[b]{2}{*}{$\begin{array}{c}\text { Fontes de } \\
\text { variação }\end{array}$} & \multirow[b]{2}{*}{ GL } & \multicolumn{5}{|c|}{$\mathrm{F}$} \\
\hline & & Peso Fruto ${ }^{* *}$ & Peso Casca ${ }^{* *}$ & Peso Polpa ${ }^{* *}$ & Diâmetro & Comprimento \\
\hline & & \multicolumn{3}{|c|}{ 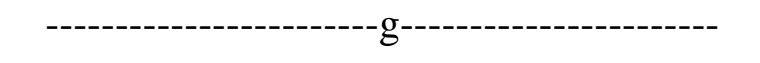 } & \multicolumn{2}{|c|}{-------------'mm-------------- } \\
\hline $\begin{array}{l}\text { Tratamen } \\
\text { to }\end{array}$ & 3 & $0,61^{\mathrm{ns}}$ & $1,18^{\mathrm{ns}}$ & $0,87^{\mathrm{ns}}$ & $0,43^{\mathrm{ns}}$ & $0,65^{\mathrm{ns}}$ \\
\hline Bloco & 2 & $0,04^{*}$ & $0,84^{\mathrm{ns}}$ & $2,51^{\mathrm{ns}}$ & $3,21^{\mathrm{ns}}$ & $0,18^{\mathrm{ns}}$ \\
\hline $\mathrm{CV}$ & & 17,04 & 15,40 & 32,75 & 9,51 & 10,58 \\
\hline MG & & 174,12 & 116,15 & 57,12 & 76,72 & 91,68 \\
\hline
\end{tabular}

* indica que o valor de F é significativo e "ns" que o valor de F não é significativo ao nível de $5 \%$ de significância. $\mathrm{CV}=$ coeficiente de variação. $\mathrm{MG}=$ média geral. $\mathrm{GL}=$ graus de liberdade. ${ }^{* *}$ Utilizou-se a transformação $\sqrt{x}$.

Observa-se pela Tabela 3, as médias obtidas para cada tratamento em função das variáveis analisadas. Nota-se que mesmo não apresentando diferença, o menor peso médio dos frutos foi de 159,59 g observado no tratamento com irrigação plena $100 \%$ da ETc alternando a cada 7 dias e o maior de 187,4 g no tratamento com irrigação plena 100\% da ETc aos dois lados.

Os resultados médios obtidos foram maiores que os observados por Hurtado-Salazar et al. (2015), com uma variação de peso dos frutos de 130,06 g a 157,43 g, avaliando duas espécies de passifloráceas silvestres como porta-enxertos relacionando com as características físicas e químicas dos frutos do maracujazeiro-amarelo em ambiente protegido. Greco et al. (2014), avaliaram frutos em 32 genótipos, e os pesos dos frutos variaram de 145,7 g a 155,6 g, menor que os obtidos neste trabalho.

Conforme Weber (2016) o peso médio encontrado na maior parte dos maracujás azedos melhorados geneticamente ficam em torno de 230 gramas. Os resultados obtidos neste trabalho também estão dentro de acordo com a informações da Embrapa a cultivar BRS Rubi do Cerrado tem seu peso dentro da faixa de 120 a 300 gramas, porém a média se concentra em 170 gramas (FALEIRO et al., 2015). 
MINAKAWA, et al.

Tabela 3. Valores médios de peso de fruto, peso da casca, peso da polpa, diâmetro e comprimento dos frutos do maracujazeiro, em relação aos tratamentos observados.

\begin{tabular}{cccccc}
\hline Tratamentos & $\begin{array}{c}\text { Peso Fruto } \\
(\mathrm{g})\end{array}$ & $\begin{array}{c}\text { Peso Casca } \\
(\mathrm{g})\end{array}$ & $\begin{array}{c}\text { Peso Polpa } \\
(\mathrm{g})\end{array}$ & $\begin{array}{c}\text { Diâmetro } \\
(\mathrm{mm})\end{array}$ & $\begin{array}{c}\text { Comprimento } \\
(\mathrm{mm})\end{array}$ \\
\hline T1 & $183,63 \mathrm{a}$ & $127,28 \mathrm{a}$ & $71,03 \mathrm{a}$ & $78,07 \mathrm{a}$ & $90,41 \mathrm{a}$ \\
T2 & $165,82 \mathrm{a}$ & $109,62 \mathrm{a}$ & $58,02 \mathrm{a}$ & $77,02 \mathrm{a}$ & $89,64 \mathrm{a}$ \\
T3 & $159,59 \mathrm{a}$ & $114,77 \mathrm{a}$ & $44,45 \mathrm{a}$ & $74,76 \mathrm{a}$ & $92,46 \mathrm{a}$ \\
T4 & $187,43 \mathrm{a}$ & $132,91 \mathrm{a}$ & $55,35 \mathrm{a}$ & $77,02 \mathrm{a}$ & $94,20 \mathrm{a}$ \\
\hline
\end{tabular}

Letras minúsculas iguais na coluna não diferem entre si de acordo com o Teste de Tukey ao nível de $5 \%$ de significância. $\mathrm{T} 1=$ redução de $25 \%$ da ETc alternando a cada 7 dias; $\mathrm{T} 2$ = redução de $50 \%$ da ETc alternando a cada 7 dias ; T3 = irrigação plena 100\% da ETc alternando a cada 7 dias e T4= irrigação plena 100\% da ETc aos dois lados.

Verifica-se pela Tabela 3 que não houve diferença entre os tratamentos no peso de casca e peso de polpa. Nota-se que a redução de $50 \%$ da ETc alternando a cada 7 dias, obteve a menor média no peso de casca e entretanto a irrigação plena alternando a cada 7 dias teve menor média em relação ao tratamento com redução de $25 \%$ da ETc e alternância a cada 7 dias, ficando este com a média próxima a encontrada no tratamento com a irrigação plena nos dois lados, indicando que o déficit de água não influenciou sobre o peso da casca.

Quanto ao peso da polpa (Tabela 3) a média do tratamento com a redução de $25 \%$ da ETc com alternância dos lados a cada 7 dias foi maior que as demais médias, enquanto as médias dos tratamentos de redução de $50 \%$ da ETc e de $100 \%$ da ETc com alternância a cada 7 dias em ambos foram bem próximas.

Para o diâmetro (Tabela 3), o tratamento que apresentou menor valor médio de diâmetro de fruto foi a irrigação plena $100 \%$ da ETc alternando a cada 7 dias $(74,76 \mathrm{~mm})$ e o maior valor $78,07 \mathrm{~mm}$ foi o verificado no tratamento com redução de $25 \%$ da ETc alternando a cada 7 dias.

Já para o comprimento médio de fruto, observou-se no tratamento com redução de 50\% da ETc alternando a cada 7 dias o menor valor $(89,64 \mathrm{~mm})$ e o maior no tratamento com irrigação plena $100 \%$ da ETc aos dois lados $(94,20 \mathrm{~mm})$ (Tabela 03).

As dimensões obtidas estão de acordo com os valores observados por Negreiros et al. (2007) e Andrade Neto et al. (2015). Com base nas dimensões, verifica-se que não houve diferença na redução de lâmina d'água aplicada, evidenciando a possibilidade de redução de água aplicada sem decréscimo significativo na qualidade dos frutos.

Através das dimensões dos frutos, pode-se observar que os frutos analisados possuíam o formato ovalado o que de acordo com Santos (2011), o formato ovalado tem preferência por parte das indústrias, pois estes apresentarem $10 \%$ a mais de suco em relação aos frutos redondos. Ainda de com Medeiros (2009), os brasileiros preferem frutos ovalados. No entanto, 
MINAKAWA, et al.

Negreiros et al. (2007), verificaram que o rendimento de polpa não apresentou relação com a forma redonda ou ovalada dos frutos.

Também observou-se que os frutos com maior diâmetro apresentaram maior peso de polpa (Tabela 3), indicando que há uma tendência de os frutos de maior diâmetro terem maior volume de suco o que também foi observado por Negreiro et al., (2007).Verifica-se que o peso da polpa foi $38,68 \%$ do peso do fruto para o tratamento com redução de $25 \%$ da ETc alternando a cada 7 dias enquanto que o tratamento irrigação plena 100\% da ETc alternando a cada 7 dias apresentou $27,85 \%$ de polpa em relação ao peso do fruto.

Observa-se através dos valores médios dos parâmetros avaliados que mesmo submetido ao maior estresse hídrico de 50\% de redução da ETc, os valores foram satisfatórios na qualidade dos frutos, o que possibilitaria a redução da lâmina bruta aplicada sem que houvesse prejuízos na qualidade física dos frutos do maracujazeiro.

Estudos realizados por Santos (2017) com mamoeiro, cultivar Tainung número 1 do grupo formosa submetido à irrigação com secamento parcial da zona radicular, irrigação fixa e irrigação plena, observou que peso médio dos frutos também não apresentou diferença, corroborando com os resultados encontrados no presente estudo.

O mesmo comportamento foi verificado em trabalho realizado por Santos et al. (2010) que verificaram que a técnica do secamento parcial com 50\% da ETc em lima ácida não diferiu do tratamento com esse mesmo déficit e sem alternância de lados da irrigação, em termos de produtividade, diâmetro e peso dos frutos, independentemente do período de alternância dos lados de irrigação.

Nota-se que a técnica de secamento parcial da zona radicular com alternância de 7 dias foi suficiente para redução da água disponível do lado submetido ao secamento para os parâmetros avaliados, permitindo a redução da lâmina de água aplicada sem interferência na produção e qualidade dos frutos do maracujazeiro.

Esta técnica é possível pois quando ocorre um intervalo em que parte da zona radicular de um lado da planta decresce a absorção de água, a planta passa à reduzir o processo transpiratório, devido ao aumento da metabolização de ácido abscísico, o que promove o fechamento parcial dos estômatos das folhas.

\section{Conclusões}

O manejo de irrigação com uso do secamento parcial aplicado no maracujazeiro não apresentou diferenças, podendo ser uma forma de economía de água sem perda significativa na qualidade de frutos. A redução de 50\% da lâmina com alternância de lados irrigados da planta 
a cada 7 dias não diferiram entre si do tratamento com aplicação da lâmina total nos dois lados da planta.

\section{Referências}

ALLEN, R. G.; PEREIRA, L. S.; RAES, D.; SMITH, M. Crop evapotranspiration: guidelines for computing crop water requirements. Rome: FAO, 1998. 300 p. (Irrigation and Drainage Paper, 56).

ALTENDORF, S. Minor tropical fruits: Mainstreaming a niche market. Food Outlook, Estados Unidos, p.69-74, 2018.

ANDRADE NETO, R. de C.; RIBEIRO, A. M. A. de S.; ALMEIDA, U. O. de; NEGREIROS, J. R. da S. Caracterização física de frutos de genótipos de maracujazeiro azedo produzido no Acre. In: ENCONTRO NACIONAL DA AGROINDÚSTRIA, 2015, Bananeiras. Semear ciência, colher tecnologia: anais. Bananeiras: Ufpb, 2015. 7 p.

ANDRADE, L. R. M. de. Corretivos e fertilizantes para culturas perenes e semiperenes. In: SOUSA, D. M. G. de; LOBATO, E. (Ed.) Cerrado: correção do solo e adubação. Planaltina, DF: Embrapa Cerrados, 2004. p. 317- 366.

ARAÚJO, H. F. de; COSTA, R. N. T.; CRISÓSTOMO, J. R.; SAUNDERS, L. C. U.; MOREIRA, O. da C.; MACEDO, A.B. M.. Produtividade e análise de indicadores técnicos do maracujazeiro-amarelo irrigado em diferentes horários. Revista Brasileira Engenharia Agrícola Ambiental, Campina Grande, v. 16, n. 2, p.159-164, 2012.

BERNARDO, S.; SOARES, A. A.; MANTOVANI, E. C. Manual de Irrigação. 8. Ed. Viçosa, MG: UFV, 2006. 625 p.

CARVALHO, A. J. C. de; MARTINS, D. P.; MONNERAT, P. H.; BERNARDO, S.; SILVA, J. A. da. Teores de nutrientes foliares no maracujazeiro-amarelo associados à estação fenológica, adubação potássica e lâminas de irrigação. Revista Brasileira de Fruticultura, [s.1.], v. 23, n. 2, p. 403-408, ago. 2001.

CARVALHO, G. C. Secamento parcial do sistema radicular no cultivo da acerola em condições do bioma da chapada diamantina. 2015. $80 \mathrm{f}$. Tese (Doutorado) - Curso de Engenharia Agrícola, Universidade Federal Rural de Pernambuco, Recife, 2015.

CASTRO P. R. C.; KLUGE, R. A. Ecofisiologia de fruteiras tropicais: abacaxizeiro, maracujazeiro, mangueira, bananeira e cacaueiro. São Paulo: Nobel, 1998. 111 p.

COSTA, A. de F. S. da; COSTA, A. N. da; VENTURA, J. A.; FANTON, C. J.; LIMA, I. de M.; CAETANO, L. C. S.; SANTANA, E. N. de.. Recomendações técnicas para o cultivo do maracujazeiro. Vitória: Incaper, 2008. 56 p.

COSTA, E. L. da; SOUSA, F. V. de; NOGUEIRA, L. C.; SATURNINO, H. M. Irrigação da cultura do maracujazeiro. Informe Agropecuário, Belo Horizonte, v. 21, n. 206, p. 59-66, 2000 . 
CRISÓSTOMO, L. A.; NAUMOV, A. Adubando para alta produtividade e qualidade: fruteiras tropicais do Brasil. Fortaleza: Embrapa Agroindústria Tropical, 2009. 238p

DAVIES, W. J.; WILKINSON, S.; LOVEYS, B. Stomatal control by chemical signalling and the exploitation of this mechanism to increase water use efficiency in agriculture. New Phytologist, v.153, p.449-460, 2002.

DAVIES, W. J.; ZHANG, J. H. Root signals and the regulation of growth and development of plants in drying soil. Annual Review of Plant Physiology and Plant Molecular Biology, v.42, p. 55-70, 1991.

DRY, P., LOVEYS, B.R. Factors influencing grapevine vigour and the potential for control with partial root-zone drying. Australian Journal of Grape and Wine Research, v.4, p. 140148, 1998.

EMBRAPA; Sistema brasileiro classificação de solos. 2. ed. EMBRAPA: São Paulo. 2006. Disponível em:<https://www.agrolink.com.br/downloads/sistema-brasileiro-de-classificacaodos-solos2006.pdf> Acesso em: 03 fev. 2020.

FALEIRO, F. G.; JUNQUEIRA, N. T. V. (Ed.). Maracujá: o produtor pergunta, a Embrapa responde. Brasília, DF: Embrapa, 2016. 341 p. (Coleção 500 perguntas, 500 respostas).

FALEIRO, F. G.; JUNQUEIRA, N. T. V.; OLIVEIRA, E. J.; MACHADO, C. F.; PEIXOTO, J. R.; COSTA, A. M.; GUIMARÃES, T. G.; JUNQUEIRA, K. P. Caracterização de germoplasma e melhoramento genético do maracujazeiro assistidos por marcadores moleculares - fase 2: resultados de pesquisa 2008-2012. Planaltina: Embrapa Cerrados, 2015.

FAO - Food and Agriculture Organization Of the United Nations. Deficit irrigation practices. Rome: FAO, p. 102, 2002. (WATER REPORTS 22).

FARQUHAR, G. D.; SHARKEY, T. D. Stomatal conductance and photosynthesis. Annual Review of Plant Physiology, v.33, p.317-345,1982.

FERREIRA, D. F. Sisvar: a computer statistical analysis system. Ciência e Agrotecnologia, v. 35, n.6, p. 1039-1042, 2011.

FLUMIGNAN, D. L.; FIGUEIREDO, L. H. S.; SILVA, J. A. da; FIETZ, C. R.; COMUNELLO, E. Evapotranspiração de referência (ETo) na região de Dourados, Mato Grosso do Sul. Dourados: Embrapa Agropecuária Oeste, 2016. 6 p. (Embrapa Agropecuária Oeste. Comunicado técnico, 215)

GOWING, D.J.; DAVIES, W.J.; JONE, H.G. A positive root-sourced signal as an indicator of soil drying, in apple, Malus x domestica Borkh. Journal of Experimental Botany, v.41, p.1535-1540, 1990.

GRECO, S. M. L.; PEIXOTO, J .R.; FERREIRA, L. M. Avaliação física, físico-química e estimativas de parâmetros genéticos de 32 genótipos de maracujazeiro-azedo cultivados no distrito federal. Bioscience Journal, Uberlândia, v.30, suppl.1,p.360-370, 2014. 
HAFLE, O.M.; RAMOS, J.D.; LIMA, L.C. de O.; FERREIRA, E.A.; MELO, P.C. de. Produtividade e qualidade de frutos do maracujazeiro-amarelo submetido à poda de ramos produtivos. Revista Brasileira de Fruticultura, Jaboticabal, v.31, n.3, 763-770, 2009.

HURTADO-SALAZAR, A.; SILVA, D. F. P. da; SEDIYAMA, C. S.; BRUCKNER, C. H. Caracterização física e química de frutos de maracujazeiro-amarelo enxertado em espécies silvestres do gênero passiflora cultivado em ambiente protegido. Revista Brasileira de Fruticultura, [S.L.], v. 37, n. 3, p. 635-643, set. 2015.

IBGE - INSTITUTO BRASILEIRO DE GEOGRAFIA E ESTATÍSTICA - Produção Agrícola Municipal - Cultura Temporárias e Permanentes : Maracujá, 2018.

INSTITUTO ADOLFO LUTZ. Normas analíticas do Instituto Adolfo Lutz. Métodos químicos e físicos de análise de alimentos. $4^{\circ}$ edição, São Paulo, 2008. p.1020.

JONES, H. G. Plants and microclimate: a quantitative approach to environmental plant physiology. 3 ed. Cambridge: Cambridge University Press, 2014.

LIMA, A. A.; BORGES, A. L.; FANCELLI, M.; CARDOSO, C. E. L. Maracujá: sistema de produção convencional. In: PIRES, M. de M.; JOSÉ, A. R. S.; CONCEIÇÃO, A. O. da (Org.). Maracujá: avanços tecnológicos e sustentabilidade. Ilhéus: Editus, 2011. 221p.

LIMA, A. A.; SANTOS FILHO, H. P.; FRANCELlI, M.; SANCHES, N. F.; BORGES, A. L. A cultura do maracujá. Brasília: EMBRAPA-SPI, 1994. 76p.

MEDEIROS, S.A.F.; YAMANISHI, O.K.; PEIXOTO, J.R.; PIRES, M.C.; JUNQUEIRA, N.T.V.; RIBEIRO, J. G.B.L. Caracterização físico-química de progênies de maracujá-roxo e maracujá-azedo cultivados no Distrito Federal. Revista Brasileira de Fruticultura., Jaboticabal, v. 31, n. 2, p. 492-499, 2009.

MELETTI, L.M.M.; OLIVEIRA, J.C.; RUGGIERO, C. Maracujá. Jaboticabal: FUNEP, 2010. (Série Frutas Nativas, 6.)

NEGREIROS, J. R. da S.; ÁLVARES, V. de S.; BRUCKNER, C. H.; MORGADO, M.Antônio D.; CRUZ, C. D. Relação entre características físicas e o rendimento de polpa de maracujáamarelo. Revista Brasileira de Fruticultura, [S.L.], v. 29, n. 3, p. 546-549, 2007.

RUGGIERO, C.; SÃO JOSÉ, A. R.; VOLPE, C. A.; OLIVEIRA, J. C. de; DURIGAN, J. F.; BAUMGARTNER, J. G.; SILVA, J. R. W.; NAKAMURA, K.; FERREIRA, M. E.; KAVATI, R.; PEREIRA, V. de P. Maracujá para exportação: aspectos técnicos da produção. Brasília, DF: EMBRAPA-SPI, 1996. 64 p. (FRUPEX. Publicações Técnicas,19).

SAMPAIO, A. H. R.; COELHO FILHO, M. A.; COELHO, E. F.; DANIEL, R.; MACHADO, V. V.; CARVALHO, G. C.; SANTANA, E. B. J. Déficit hídrico e secamento parcial do sistema radicular em pomar de lima ácida. Pesquisa Agropecuária Brasileira, v.45, n.10, p.11411148, 2010.

SANTOS, C. E. M. dos; BRUCKNER, C. H.; CRUZ, C. D.; SIQUEIRA, D. L. de; PIMENTEL, L. D.. CARACTERÍSTICAS FÍSICAS DO MARACUJÁ-AZEDO EM FUNÇÃO DO 
GENÓTIPO E MASSA DO FRUTO. Revista Brasileira de Fruticultura, Jaboticabal, v. 31, n. 4, p.1102-1110, 2009.

SANTOS, D. L.. Efeito do secamento parcial da zona radicular do mamoeiro (Carica papaya L.) em uma condição edafoclimática do semiárido da Bahia. 2017. 70 f. Dissertação (Mestrado) - Curso de Engenharia Agrícola, Universidade Federal de Viçosa, Viçosa, 2017.

SANTOS, J. L. V. dos. Qualidade dos frutos e ponto de colheita das cultivares de maracujá: BRS gigante amarelo, BRS ouro vermelho, BRS sol do cerrado. 2011. $124 \mathrm{f}$. Dissertação (Mestrado) - Curso de Produção Vegetal, Centro de Ciências e Tecnologias Agropecuárias, Universidade Estadual do Norte Fluminense Darcy Ribeiro, Campos dos Goytacazes, 2011.

SATO, G. S.; CHABARIBERY, D.; BESSA JÚNIOR, A. de A.. PANORAMA DA PRODUÇÃO E DE MERCADO DO MARACUJÁ. Informações Econômicas, São Paulo, v. 22, n. 6, p.17-30, 1992.

SOUSA, V. F. de; BORGES, A. L. Irrigação e fertirrigação na cultura do maracujá. In: SOUSA, V. F. de; MAROUELli, W. A.; COELHO, E. F.; PINTO, J. M.; COELHO FILHO, M. A. (Ed.). Irrigação e fertirrigação em fruteiras e hortaliças. Brasília, DF: Embrapa Informação Tecnológica, 2011. Cap. 17, p. 501-522.

SOUSA, V. F. de; BORGES, A. L.; COELHO, E. F.; VASCONCELOS, L. F. L.; VELOSO, M. E. da C.; OLIVEIRA, Á. S. de; NETTO, A. de O. A.. Irrigação e Fertirrigação do Maracujazeiro. 32. ed. Teresina: Embrapa Meio-norte, 2001. 46 p.

WEBER, D. Avaliação de maracujazeiros em condições de clima temperado : produção, qualidade e compostos bioativos. 2016. 124 f. Tese (Doutorado) — Programa de PósGraduação em Agronomia. - Faculdade de Agronomia Eliseu Maciel, Universidade Federal de Pelotas, Pelotas, 2016. 